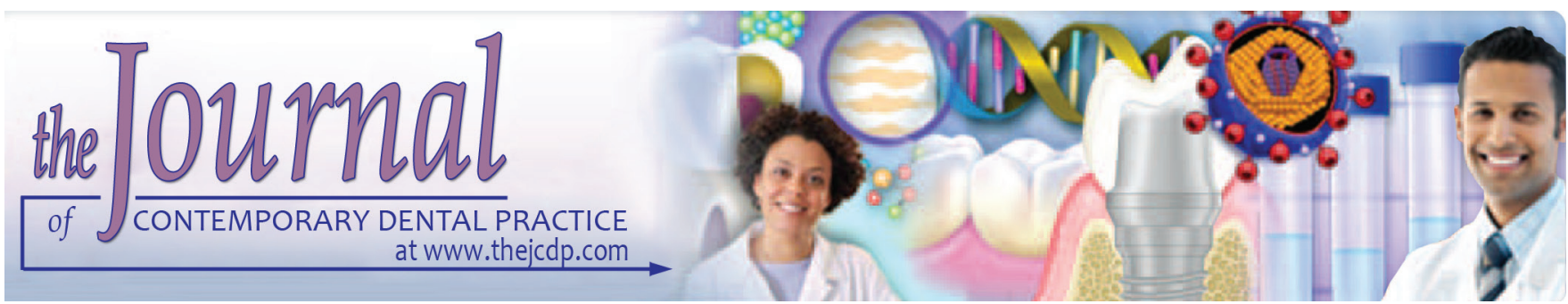

\title{
Evaluation of the Effects of Fluoride Prophylactic Agents on Mechanical Properties of Nickel Titanium Wires using Scanning Electron Microscope
}

${ }^{1}$ Ajay K Gupta, ${ }^{2}$ Gita Shukla, ${ }^{3}$ Poonam Sharma, ${ }^{4}$ Amit K Gupta, ${ }^{5}$ Amit Kumar, ${ }^{6}$ Deepika Gupta

\begin{abstract}
Introduction: Orthodontic treatment these days is increasing in demand, and therefore, it is relatively imperative for the orthodontist to prescribe the use of fluoride-containing products, such as mouthwashes and gels, to help prevent dental caries and maintain healthy oral health. The aim of the study was to assess and evaluate the effects of fluoride prophylactic agents on mechanical properties of nickel titanium (NiTi) wires during orthodontic treatment using scanning electron microscope (SEM).
\end{abstract}

Materials and methods: We used the commercially available round preformed $\mathrm{NiTi}$ orthodontic archwire (3M company) and three different mouthwash solutions, i.e., Phos-Flur gel $(1.1 \%$ sodium acidulated phosphate fluoride, APF, $0.5 \% \mathrm{w} / \mathrm{v}$ fluoride, $\mathrm{pH}=5.1$; Colgate Oral Pharmaceuticals) and Prevident 5000 (1.1\% sodium fluoride neutral agent, $0.5 \% \mathrm{w} / \mathrm{v}$ fluoride, $\mathrm{pH}$ = 7; Colgate Oral Pharmaceuticals). All the specimens were subjected to a three-point bending test on a universal testing machine. To observe the surface morphological changes, one wire from each group was randomly selected and observed under a SEM.

\begin{tabular}{l}
\hline $\begin{array}{l}\text { Please provide department } \\
\text { author 2,4,5,6 if any }\end{array}$ \\
$\begin{array}{l}\text { thopedics, Shree } \\
\text { ntre, Ghaziabad }\end{array}$ \\
${ }^{3}$ Dr. Gepartment of Orthodontics and Dentofacial Orthopedics \\
Employees' State Insurance Corporation Dental College \& \\
Hospital, Rohini, New Delhi, India \\
${ }^{4}$ Dentavista Super Speciality Dental Clinic \& Orthodontic Center \\
New Delhi, India \\
${ }^{5}$ Dental Health Centre, Ghaziabad, Uttar Pradesh, India \\
${ }^{6}$ Align Dentals, Noida, Uttar Pradesh, India \\
Corresponding Author: Ajay K Gupta, Department of \\
Orthodontics and Dentofacial Orthopedics, Shree Bankey \\
Bihari Dental College and Research Centre, Ghaziabad, Uttar \\
Pradesh, India, Phone: +919818758144, e-mail: drajaygupta04 \\
@gmail.com
\end{tabular}

Results: It was observed that there was not much difference in the values of both modulus of elasticity and yield strength obtained after loading of stress on the wires in all the three experimental conditions. A significant difference in both modulus of elasticity and yield strength was observed during unloading of stress. Further, when the surface characteristics were observed for all the specimens using SEM images, it was observed that NiTi wires treated with Phos-Flur showed large surface defects which appeared as round, pitted areas depicting corrosion, numerous white inclusions, and overall damaged surface structure of the wire as compared with the control.

Conclusion: Thus, fluoridated mouthwashes are essential to maintain good oral hygiene and decrease instance of caries in patients undergoing orthodontic treatment. The prophylactic usage of topical fluoride agents on NiTi wire seems to diminish the mechanical properties of the orthodontic wire that could significantly affect future treatment outcomes.

Clinical significance: It has been proved that fluoride mouthwashes/gels do affect the structural surface qualities and strength of wires used during the orthodontic treatment irrespective of the composition of the wires. Therefore, it is the responsibility of the clinician to prescribe these prophylactic agents carefully while keeping in mind their $\mathrm{pH}$ so that the overall result of the treatment may not be hampered and delayed due to change in properties of the wires used.

Keywords: Fluoride mouthwashes, Mechanical properties, Nickel titanium wires, Scanning electron microscope.

How to cite this article: Gupta AK, Shukla G, Sharma P, Gupta AK, Kumar A, Gupta D. Evaluation of the Effects of Fluoride Prophylactic Agents on Mechanical Properties of Nickel Titanium Wires using Scanning Electron Microscope. J Contemp Dent Pract 2018;19(3):283-286.

Source of support: Nil

Conflict of interest: None

\section{INTRODUCTION}

Orthodontic treatment these days is increasing in demand and becoming a more common practice for improvement 
in the esthetic quality not only in children but also in adults. Commonly used titanium-based archwires in orthodontic practice are known for their good quality, pseudoelastic properties, and high corrosion resistance due to formation of a stable oxide layer. ${ }^{1,2}$ For a patient undergoing orthodontic treatment, it is important for the orthodontist to prescribe the use of fluoride-containing products, such as mouthwashes and gels to help prevent dental caries and maintain healthy oral health., ${ }^{3,4}$ Most commonly prescribed fluoride mouthwashes are available in 0.05 and $0.2 \%$ fluoride concentrations, which have to be used weekly and even daily to prevent caries. Thus, the orthodontic wires are continuously being exposed to fluorides which may affect their properties and quality. ${ }^{5}$ Nickel titanium archwires are known to be comparatively more stable and resistant to corrosion than stainless steel archwires. Many studies have also reported a negative effect on the corrosion resistance of NiTi wires. ${ }^{6,7}$ However, still, little information is available in the literature on the adverse effects of such materials on orthodontic wires. Thus, the aim of this in vitro study was to assess and evaluate the effects of fluoride prophylactic agents on mechanical properties of NiTi wires during orthodontic treatment using SEM.

\section{MATERIALS AND METHODS}

For the present study, we used the commercially available round preformed NiTi orthodontic archwire (3M, Inc., Minnesota, USA) and three different mouthwash solutions. The fluoride agents selected in the study were those commonly prescribed by the orthodontists in their clinical practice. The fluoride agents thus used were PhosFlur gel (1.1\% sodium APF, $0.5 \% \mathrm{w} / \mathrm{v}$ fluoride, $\mathrm{pH}=5.1$; Colgate Oral Pharmaceuticals) and Prevident 5000 (1.1\% sodium fluoride neutral agent, $0.5 \% \mathrm{w} / \mathrm{v}$ fluoride, $\mathrm{pH}=7$; Colgate Oral Pharmaceuticals). The archwire was cut into 0.017 " $\times 0.25$ " segments and was immersed in $5 \mathrm{~mL}$ of the respective fluoride solutions in glass containers and incubated at $37^{\circ} \mathrm{C}$ for 1.5 hours. For the control group, we used deionized water as a solution. After the predetermined time, all the specimens were removed from the solutions and rinsed properly with distilled water and were then transferred to the other new vials and sent for mechanical testing. For mechanical testing, the specimens were tested in a heated distilled water bath $\left(37^{\circ} \mathrm{C}\right)$ to simulate the aqueous oral environment. All the specimens were subjected to a three-point bending test on a universal testing machine. Compressive load was applied using the machine with a crosshead speed of $0.5 \mathrm{~mm} / \mathrm{min}$ to the center of each wire. Each specimen was loaded to a deflection of $2.5 \mathrm{~mm}$ and then unloaded to zero deflection at a crosshead speed of $1 \mathrm{~mm} / \mathrm{min}$. To observe the surface morphological changes, one wire from each group was randomly selected and observed under a SEM.

\section{Statistical Significance and Results}

All the observations of the mechanical properties were calculated and tabulated for comparison and sent for statistical analysis. Statistical analysis was carried out using Statistical Package for the Social Sciences software, version 21 (SPSS Inc., Chicago, IL, USA). Analysis of variance test was used to test the level of significance; $\mathrm{p}<0.05$ was considered to be statistically significant for all the tests. All the results were analyzed and were tabulated. Each wire was analyzed in three different mediums, and means of modulus of elasticity and yield strength were calculated both while loading and unloading (Table 1). It was observed that there was not much of difference in the values of both modulus of elasticity and yield strength obtained after loading of stress on the wires in all the three experimental conditions. Also, a significant difference in both modulus of elasticity and yield strength was found during unloading of stress. When both the fluoride gels were compared with the control, it was observed that these fluoride gels significantly decreased the modulus of elasticity and yield strength during unloading forces. Further, when the surface characteristics were observed for all the specimens using SEM images, it was observed that NiTi wires treated with Phos-Flur showed large surface defects which appeared as round, pitted areas depicting corrosion, numerous white inclusions, and overall damaged surface structure of the wire as compared with the control (Figs 1 and 2). Next, for the NiTi wire treated with Prevident, it was observed that the

Table 1: Loading and unloading properties of NiTi wires after treatment in different solutions

\begin{tabular}{llllll}
\hline $\begin{array}{l}\text { Type of } \\
\text { wire }\end{array}$ & Treatment done & $\begin{array}{l}\text { Mean of modulus of } \\
\text { elasticity on loading } \\
\text { (GPa) }\end{array}$ & $\begin{array}{l}\text { Mean of modulus of } \\
\text { elasticity on unloading } \\
\text { (GPa) }\end{array}$ & $\begin{array}{l}\text { Mean of yield } \\
\text { strength on loading } \\
\text { (MPa) }\end{array}$ & $\begin{array}{l}\text { Mean of yield } \\
\text { strength on unloading } \\
\text { (MPa) }\end{array}$ \\
\hline $\mathrm{NiTi}$ & Distilled water (control) & $62.40 \pm 2.5$ & $61.80 \pm 3.5$ & $2360 \pm 560.12$ & $1523 \pm 80.42$ \\
& Phos-Flur gel & $61.25 \pm 2.7$ & $61.15 \pm 2.9$ & $2120 \pm 480.34$ & $1422 \pm 52.30$ \\
& Prevident & $60.40 \pm 1.8$ & $60.30 \pm 1.2$ & $2128 \pm 320.32$ & $1211 \pm 51.22$ \\
Cu-NiTi & Distilled water (control) & $56.42 \pm 2.82$ & $56.40 \pm 3.50$ & $3018 \pm 540.12$ & $1483 \pm 28.35$ \\
& Phos-Flur gel & $57.19 \pm 2.13$ & $57.18 \pm 2.30$ & $2860 \pm 360.12$ & $1327 \pm 42.13$ \\
& Prevident & $56.21 \pm 2.05$ & $54.25 \pm 3.48$ & $2540 \pm 560.12$ & $1214 \pm 32.20$ \\
\hline
\end{tabular}




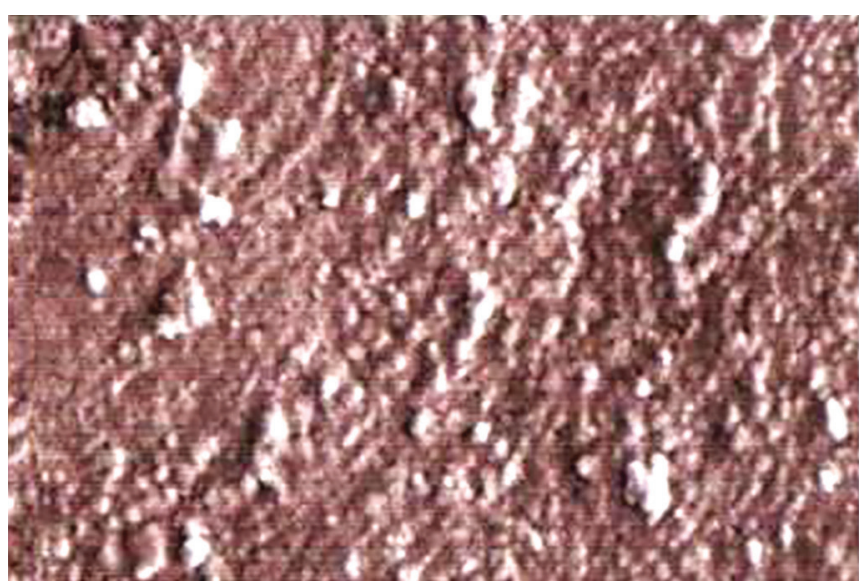

Fig. 1: Scanning electron microscope images showing treatment with distilled water

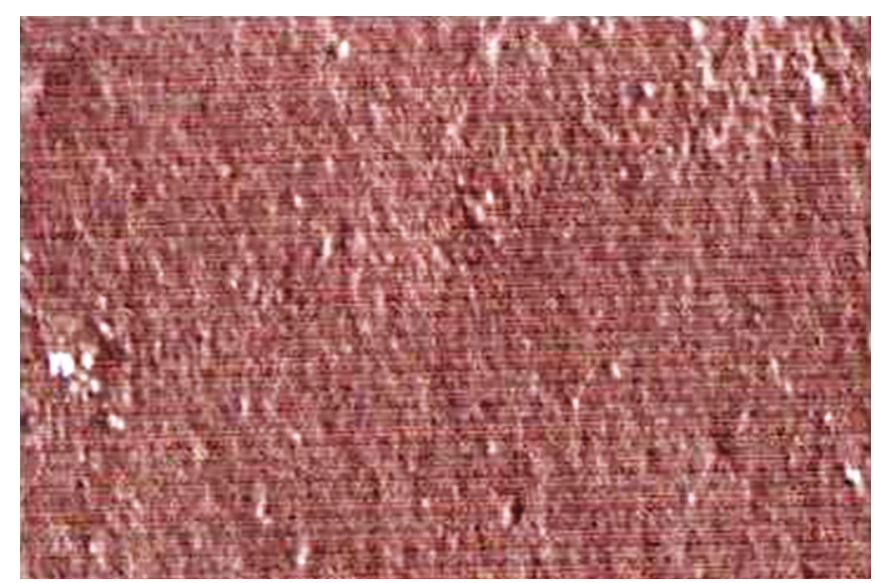

Fig. 3: Scanning electron microscope images showing treatment with Prevident gel

surface changes, such as dark areas, white inclusions, and pitting corrosion were present, but they were less severe as compared with the results of Phos-Flur gel and the control (Fig. 3).

\section{DISCUSSION}

Usually, it is observed that orthodontic treatment is accompanied by compromised oral hygiene that can lead to demineralization of the teeth and later can progress to caries. Accumulation of plaque on the brackets and wires and inability to clean these areas can lead to such major problems. Many patients with periodontal problems during orthodontic treatment develop caries and for this they need different mouthwashes to reduce plaque accumulation. Various studies have reported that only $2 \%$ of patients using fluoride applications developed white spot lesions, whereas about $58 \%$ of patients who did not practice any fluoride application developed lesions. ${ }^{8,9}$ Thus, the importance of using fluorides during orthodontic treatment in preventing caries and periodontal problems is justified. Thus, prescribing mouthwashes is a common practice for the orthodontists. Within the brackets, the

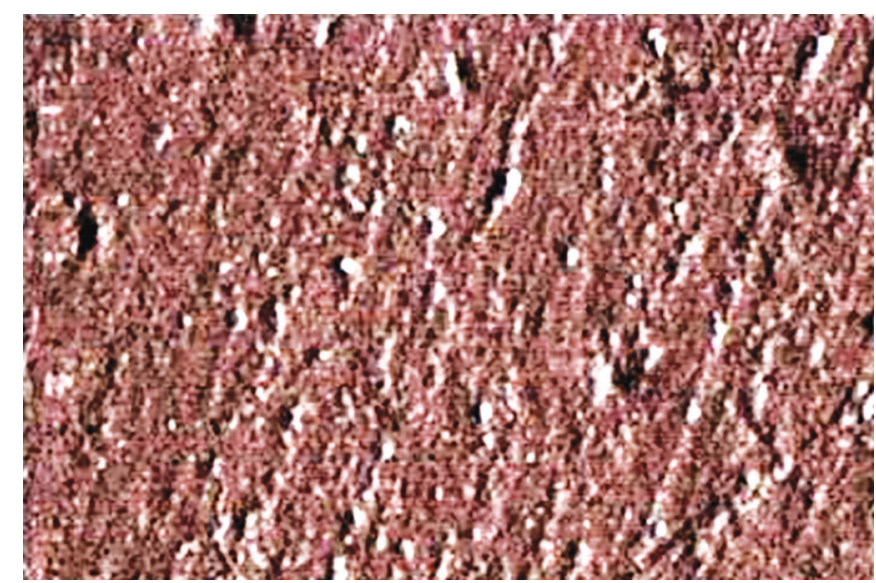

Fig. 2: Scanning electron microscope images showing treatment with Phos-Flur gel

efficacy of the sliding mechanics of the wires is affected by the friction produced between the two interfaces. Smoothness of wire plays a major role in this mechanics. Any alteration in the surface of the wire or the structural changes will definitely compromise the sliding property of the archwires in the brackets, thereby affecting ultimately the forces and tooth movement and the treatment outcome.

The commonly used titanium-based archwires in orthodontic practice are known for their good quality, pseudoelastic properties, and high corrosion resistance due to formation of a stable oxide layer as a result of passivation. Metallic materials are found to be nonsusceptible to corrosion as long as the surface oxide film is intact. However, once the oxide layer dissolves, there occurs surface structural changes, such as corrosion and pitting on the surface of the wire. ${ }^{6,10}$ The results of our study showed a significant difference in both modulus of elasticity and yield strength during loading and unloading of stress. Further, when both the fluoride gels were compared with the control, it was observed that these fluoride gels significantly decreased the modulus of elasticity and yield strength during unloading forces. Our results were in accordance with the study of Koushik et $\mathrm{al}^{11}$ who also reported similar findings in their study. On the contrary, Schwaninger and Sarkar, ${ }^{12}$ when evaluated the flexural properties, such as modulus of stiffness, flexural yield strength, and fatigue after treatment of wires, concluded that corrosion does not affect the archwire properties. Hammad et $\mathrm{al}^{13}$ in their study on the mechanical and surface properties of translucent composite wires after fluoride treatment, found that fluoride therapy significantly decreased the strength of composite wires in comparison with a distilled water control group. Yokoyama et $\mathrm{al}^{14}$ in their study explained the reason for the ductility loss and the reduction in the tensile strength of the workhardened NiTi alloy in 2.0\% APF solution. They suggested that there is a formation of a brittle layer at the peripheral 
part of the cross-section which is associated with rapid absorption of hydrogen. Thus, it can be stated that the fluoride applications can cause an increase in absorption of hydrogen on the surface of the wires and can lead to corrosion and pitting. In our study, we used two fluoride prophylactic preparations, of which one had a $\mathrm{pH}$ of 5.1 and the other one of 7 . The association of corrosion and the $\mathrm{pH}$ of the fluoride solution used is also a significant relation. Nakagawa et a ${ }^{15}$ described the importance of this relation. They reported that the corrosion of titanium archwires is enhanced in an acidic environment because $\mathrm{F}$ ion in the solution combines with $\mathrm{H}^{+}$ions to form $\mathrm{HF}$, even if the NaF concentration is low. Watanabe and Watanabe ${ }^{16}$ reported an increase in the surface roughness of NiTi-based archwires on exposure to fluoride treatment or application. Walker et $\mathrm{al}^{1}$ also reported an increase in surface roughness, corrosion, pitting, and presence of inclusion bodies on the surface of the NiTi wires after exposure to the fluoride prophylactic agents.

Further, when surface topography was evaluated using SEM, it was observed that NiTi wires treated with Phos-Flur showed large surface defects which appeared as round, pitted areas depicting corrosion, numerous white inclusions, and overall damaged surface structure of the wire as compared with the control and the ones treated with Prevident. Thus, here also, our results prove that both $\mathrm{pH}$ and fluoride concentrations are important factors related to surface corrosion of titanium-based alloys. The surface changes were found to be more pronounced in the $\mathrm{Cu}-\mathrm{NiTi}$ archwires, which can be explained due to the presence of metallic copper resulting in increased susceptibility to pitting corrosion. Heravi et $\mathrm{al}^{17}$ in their study using SEM demonstrated that the shape of corrosion pits was also different for different NiTi group wires and its smoother surface contrasted the rough surface of other wires. They explained this based on the cold working/ manufacturing of these wires.

Thus, the clinical significance of our study lies in the fact that it has been proved that fluoride mouthwashes/ gels do affect the structural surface qualities and strength of archwires used during the orthodontic treatment irrespective of the composition of the wires. Thus, it is the responsibility of the doctor to prescribe these prophylactic agents carefully while keeping in mind their $\mathrm{pH}$ so that the overall result of the treatment may not be hampered and delayed due to change in properties of the wires used.

\section{CONCLUSION}

Fluoridated mouthwashes are a must to maintain the good oral hygiene and decrease instance of caries in patients undergoing orthodontic treatment. However, along with this, they have adverse effects on the quality of the wires and properties as well. Thus, such prophylactic agents should be used with caution and there occurs need of new mouthwashes with less deleterious effects on the mechanical properties of the archwires used for orthodontic treatment.

\section{REFERENCES}

1. Walker MP, White RJ, Kula KS. Effect of fluoride prophylactic agents on the mechanical properties of nickel-titanium-based orthodontic wires. Am J Orthod Dentofacial Orthop 2005 Jun;127(6):662-669.

2. Kusy RP. A review of contemporary archwires: their properties and characteristics. Angle Orthod 1997;67(3):197-207.

3. Schiff N, Boinet M, Morgon L, Lissac M, Dalard F, Grosgogeat B. Galvanic corrosion between orthodontic wires and brackets in fluoride mouthwashes. Eur J Orthod 2006 Jun;28(3):298-304.

4. Matasa CG. Microbial attack of orthodontic adhesives. Am J Orthod Dentofacial Orthop 1995 Aug;108(2):132-141.

5. Li X, Wang J, Han EH, Ke W. Influence of fluoride and chloride on corrosion behavior of NiTi orthodontic wires. Acta Biomater 2007 Sep;3(5):807-815.

6. Schiff N, Grosgogeat B, Lissac M, Dalard F. Influence of fluoride content and $\mathrm{pH}$ on the corrosion resistance of titanium and its alloys. Biomaterials 2002 May;23(9):1995-2002.

7. Boere G. Influence of fluoride on titanium in an acidic environment measured by polarization resistance technique. J Appl Biomater 1995 Winter;6(4):283-288.

8. Vorhies AB, Donly KJ, Staley RN, Wefel JS. Enamel demineralization adjacent to orthodontic brackets bonded with hybrid glass ionomer cements: an in vitro study. Am J Orthod Dentofacial Orthop 1998 Dec;114(6):668-674.

9. Todd MA, Staley RN, Kanellis MJ, Donly KJ, Wefel JS. Effect of a fluoride varnish on demineralization adjacent to orthodontic brackets. Am J Orthod Dentofacial Orthop 1999 Aug;116(2):159-167.

10. Kim H, Johnson JW. Corrosion of stainless steel, nickeltitanium, coated nickel-titanium, and titanium orthodontic wires. Angle Orthod 1999 Feb;69(1):39-44.

11. Koushik SR, Hegde N, Mahesh CM, Chandrashekar BS, Shetty B, Mahendra S. Effect of fluoride prophylactic agents on the mechanical properties of nickel-titanium wires: an in vitro Study. J Indian Orthod Soc 2011 Oct-Dec;45(4):237-242.

12. Schwaninger B, Sarkar NK, Foster BE. Effect of long-term immersion corrosion on the flexural properties of nitinol. Am J Orthod 1982 Jul;82(1):45-49.

13. Hammad SM, Al-Wakeel EE, Gad el-S. Mechanical properties and surface characterization of translucent composite wire following topical fluoride treatment. Angle Orthod 2012 Jan;82(1):8-13.

14. Yokoyama K, Kaneko K, Ogawa T, Moriyama K, Asaoka K, Sakai J. Hydrogen embrittlement of work-hardened Ni-Ti alloy in fluoride solutions. Biomaterials 2005 Jan;26(1):101-108.

15. Nakagawa M, Matsuya S, Shiraishi T, Ohta M. Effect of fluoride concentration and $\mathrm{pH}$ on corrosion behavior of titanium for dental use. J Dent Res 1999 Sep;78(9):1568-1572.

16. Watanabe I, Watanabe E. Surface changes induced by fluoride prophylactic agents on titanium-based orthodontic wires. Am J Orthod Dentofacial Orthop 2003 Jun;123(6):653-656.

17. Heravi F, Moayed MH, Mokhber N. Effect of fluoride on nickel-titanium and stainless steel orthodontic archwires: an in-vitro study. J Dent (Tehran) 2015 Jan;12(1):49-59. 